\title{
Development of a test strip for rapid detection of lactoperoxidase in raw milk ${ }^{*}$
}

\author{
Hong-xia CHE, Bo TIAN, Li-na BAI, Li-ming CHENG, Li-li LIU, \\ Xiao-na ZHANG, Zhan-mei JIANG ${ }^{\dagger+}$, Xiao-xi XU ${ }^{\dagger \ddagger}$ \\ (Key Laboratory of Dairy Science (KLDS), Ministry of Education, Northeast Agricultural University, Harbin 150030, China) \\ †E-mail: zhanmeijiang@neau.edu.cn; xiaoxi_xu01@163.com \\ Received Dec. 20, 2014; Revision accepted May 11, 2015; Crosschecked July 9, 2015
}

\begin{abstract}
Traditional methods for detecting lactoperoxidase (LP) are complex and time-consuming, so a test strip was made based on the enzymatic reaction principle to enable quick and convenient detection of LP in raw milk. In this study $0.1 \mathrm{~mol} / \mathrm{L}$ citric acid (CA)/0.2 mol/L disodium hydrogen phosphate (NaP) buffer solution $(\mathrm{pH} 5.0), 22 \mathrm{mmol} / \mathrm{L}$ 3,3',5,5'-tetramethylbenzidine (TMB), $0.6 \mathrm{mmol} / \mathrm{L}$ hydrogen peroxide $\left(\mathrm{H}_{2} \mathrm{O}_{2}\right)$, and $0.5 \%$ Tween-20 or $0.3 \%$ cetyltrimethyl ammonium bromide (CTAB) were optimal for preparing a quick, sensitive, and accurate LP test strip. The coefficient of variation (CV) of the estimated LP concentrations ranged from $2.47 \%$ to $6.72 \%$ and the minimum LP concentration detected by the test strip was 1-2 mg/L. Estimates of active LP in sixteen raw milk samples obtained using the test strip or the TMB method showed a good correlation $(r=0.9776)$. So the test strip provides a quick, convenient, and accurate method for detecting the LP concentration of raw milk.
\end{abstract}

Key words: Lactoperoxidase, Test strip, Rapid detection, Raw milk, 3,3',5,5'-Tetramethylbenzidine (TMB) doi: $10.1631 /$ jzus.B1400359

Document code: A

CLC number: TS252.7

\section{Introduction}

Lactoperoxidase (LP, EC 1.11.1.7) is a member of the peroxidase family, a group of natural enzymes, and consists of a single polypeptide chain containing 612 amino acid residues. Its molecular mass is about $78 \mathrm{kDa}$ (Singh et al., 2008). LP is widely distributed in the mammary, salivary, and lacrimal glands and their secretions (Kussendrager and van Hooijdonk, 2000; Montiel et al., 2012). LP is one of the most heat stable enzymes in milk (Griffiths, 1986; Shakeel-urRehman and Farkye, 2003) and its destruction has

\footnotetext{
Corresponding authors

* Project supported by the National "Twelfth Five-Year" Plan for Science and Technology Support Program of China (No. 2013BAD18B06) the Open Research Fund for the Key Laboratory of Dairy Science of Northeast Agricultural University (No. KLDS201201), and the Innovative Research Team of Higher Education of Heilongjiang Province (No. 2010td11), China

(10) ORCID: Zhan-mei JIANG, http://orcid.org/0000-0002-7296-658X

(C) Zhejiang University and Springer-Verlag Berlin Heidelberg 2015
}

been used as an index of the pasteurization efficiency of raw milk. LP is only partially inactivated by short pasteurization at $74{ }^{\circ} \mathrm{C}$ (Wolfson and Sumner, 1993). Marks et al. (2001) confirmed that LP retains its activity during normal pasteurization $\left(63{ }^{\circ} \mathrm{C}\right.$ for $30 \mathrm{~min}$ or $72{ }^{\circ} \mathrm{C}$ for $15 \mathrm{~s}$ ), but is destroyed by pasteurization at $80{ }^{\circ} \mathrm{C}$ for $4 \mathrm{~s}$ (Seifu et al., 2005). LP is also used as diagnostic indicator of subclinical mastitis in cows' milk (Isobe et al., 2011). LP and thiocyanate, together with hydrogen peroxide $\left(\mathrm{H}_{2} \mathrm{O}_{2}\right)$, forms the LP system (LPS), which is considered to be the most significant microbial inhibitor, not only in milk and milk products (Boulares et al., 2011), but also in fish farming and functional foods (van Hooijdonk et al., 2000). LP has also been shown to have medicinal value (Tenovuo, 2002; Shimizu et al., 2011). Due to the important applications of LP, it is important to be able to detect its activity in milk and milk products during their processing, transportation, and storage.

Many methods for detecting LP have been reported, mostly based on color reactions. Kumar and Bhatia 
(1999) used 2,2'-azinobis-(3-ethyl benzthiazoline6-sulphonie acid) (ABTS) as a chromogenic substrate to standardize a spectrophotometric method to measure LP activity in milk. ABTS and guaiacol were used as detection substrates to study the effect of high pressure treatment on denaturation of LP (Pinho et al., 2011; Mazri et al., 2012). Fonteh et al. (2005) verified that LP activity is affected by various compounds present in the ABTS reaction system. 3,3',5,5'Tetramethylbenzidine (TMB) was used to detect LP activity in human milk (Shin et al., 2000). In these LP detection methods, milk samples must be pretreated, the detection procedures are complex, and highly skilled laboratory technicians and sophisticated equipment are needed. Therefore, the development of a quick and convenient LP detection method with high sensitivity and accuracy is of great importance theoretically and practically for the collection of raw milk and online processing of dairy products containing LP. In this study, based on the enzymatic reaction, TMB was used as the chromogenic substrate to develop a rapid and simple test strip for LP detection for use in the processing of raw milk and related milk products containing LP.

\section{Materials and methods}

\subsection{Materials}

Commercial bovine LP (EC 1.11.1.7) and Triton $\mathrm{X}-100$ were purchased from the Sigma Chemical Co. (St. Louis, USA). TMB was obtained from Yuanye Biotechnology Co. Ltd. (Shanghai, China). $\mathrm{H}_{2} \mathrm{O}_{2}$ solution (30\%) was supplied by the Tianli Chemical Reagent Co. Ltd. (Tianjin, China). Polyvinyl chloride (PVC) offset, used to fix the test strips, was purchased from the Shanghai Kingbo Biotech Co. Ltd. (Shanghai, China). All other reagents were of analytical grade.

\subsection{Preparation of test strips}

Homogeneous buffer solution $(10 \mathrm{ml})$ and TMB solution $(0.25 \mathrm{ml})$ were freshly prepared and mixed. Surfactant solution $(0.5 \mathrm{ml})$ was added to this mixture, which was then stirred gently for $2 \mathrm{~min}$. Subsequently, a piece of filter paper $(3 \mathrm{~cm} \times 5 \mathrm{~cm})$ was steeped in the solution for 1-3 min. The test strip was dried for
$20 \mathrm{~min}$ in a vacuum drying chamber at $35^{\circ} \mathrm{C}$. Finally, the test strip was cut into sections $(0.5 \mathrm{~cm} \times 0.5 \mathrm{~cm})$ using a strip cutter, and pasted onto a PVC offset used as the reaction zone.

\subsection{LP detection using the test strip}

An aliquot of $\mathrm{H}_{2} \mathrm{O}_{2}(3 \mu \mathrm{l})$ was added to the test strip. Subsequently, $3 \mu$ of a milk sample was also placed on the test strip. After 3 min of the chromogenic reaction, the test strip was placed in the detection zone of the color analyzer. The reflection intensity of the test strip was measured and recorded at $655 \mathrm{~nm}$. A flow chart of the method for detecting active LP in a milk sample is shown in Fig. 1. The lower the reflective intensity, the higher the concentration of active LP detected in the milk sample. Control measurements were obtained using milk samples not containing LP. Each experiment was carried out three times.

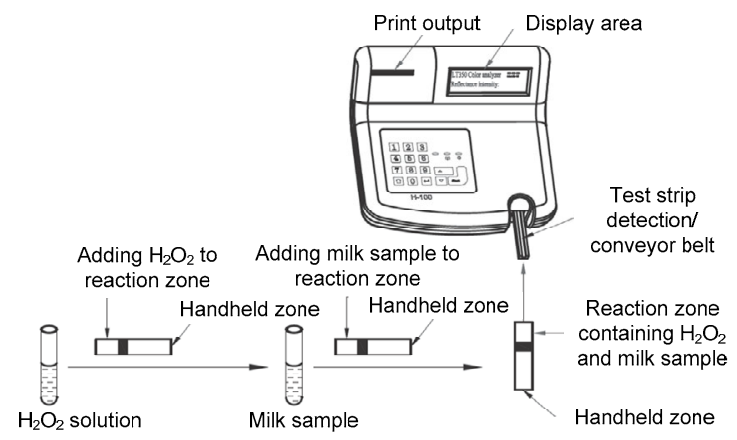

Fig. 1 Detection flow chart of active $L P$ in a milk sample

The color analyzer consists of mechanical, optical, and circuit systems. The mechanical system includes mainly transfer, sampling, and testing devices. The optical system comprises an optical source, a monochrome processor, and photoelectric exchange equipment. A light emitting diode (LED) is used as the optical source and is fixed above the reaction zone of the color analyzer, which can emit light at a specific wavelength. First, reflection intensity signals are converted into specific digital signals by photoelectric conversion, signal amplification, and analog/digital (A/D) conversion. Subsequently, the digital signals are processed and converted to display data (reflective intensity values). Finally, reflective intensity values are printed. 


\subsection{Optimization of preparation of the test strip for LP detection}

2.4.1 Effects of $\mathrm{pH}$ of the buffer solution on test strip detection

In the preparation of the test strip, to investigate the effect of the $\mathrm{pH}$ of the buffer, the $\mathrm{pH}$ values of the $0.1 \mathrm{~mol} / \mathrm{L}$ citric acid $(\mathrm{CA}) / 0.2 \mathrm{~mol} / \mathrm{L}$ disodium hydrogen phosphate (NaP) buffer solution were adjusted to $4.0,4.4,5.0,5.4$, or 6.0. Subsequently, these buffer solutions $(10 \mathrm{ml})$ were mixed with $0.25 \mathrm{ml}$ of TMB solution and $0.5 \mathrm{ml}$ of surfactant solution. The test strip was prepared using the above mixture, and LP was detected using the color analyzer.

2.4.2 Effects of TMB concentration on test strip detection

TMB was used as the chromogenic agent in the detection system. TMB solutions at concentrations of $10,15,20$, and $25 \mathrm{mmol} / \mathrm{L}$ were prepared. A total of $0.25 \mathrm{ml}$ of different concentrations of TMB solution were mixed with $10 \mathrm{ml}$ of buffer solution and $0.5 \mathrm{ml}$ of surfactant solution. The test strip was prepared using the above mixture and LP was detected using the color analyzer.

2.4.3 Effects of $\mathrm{H}_{2} \mathrm{O}_{2}$ concentration on test strip detection

$\mathrm{H}_{2} \mathrm{O}_{2}(3 \mu \mathrm{l})$ at concentrations of $0.5,0.6,0.7,0.8$, 0.9 , or $1.2 \mathrm{mmol} / \mathrm{L}$ was added to the reaction zone of the test strip, followed by $3 \mu 1$ of LP sample. LP on the test strip was detected using the color analyzer.

\subsubsection{Effects of surfactant selection on test strip detection}

To enhance the sensitivity and uniformity of detection, $0.5 \%(5 \mathrm{~g} / \mathrm{L})$ sodium dodecyl sulfate (SDS), $0.3 \%$ Triton X-100, 0.3\% (3 g/L) cetyltrimethyl ammonium bromide (CTAB), and $0.5 \%$ Tween-20 were used as surfactants in the preparation of the test strips.

\subsection{Determination of LP concentration by the TMB method}

LP was determined spectrophotometrically using a UV-visible spectrophotometer (UV-2401PC, Shimadzu, Co. Ltd., Japan). The reaction mixture consisted of $2 \mathrm{ml}$ of $0.1 \mathrm{~mol} / \mathrm{L} \mathrm{CA} / 0.2 \mathrm{~mol} / \mathrm{L} \mathrm{NaP}$ buffer solution ( $\mathrm{pH} 4.8$ ), $0.05 \mathrm{ml}$ of $20 \mathrm{mmol} / \mathrm{L} \mathrm{TMB}$ solution, and $0.3 \mathrm{ml}$ of $0.6 \mathrm{mmol} / \mathrm{L} \mathrm{H}_{2} \mathrm{O}_{2}$. The reac- tion was started by adding $0.1 \mathrm{ml}$ of LP sample. After vortexing for $3.5 \mathrm{~min}$ at room temperature, absorbance $(y)$ was recorded at $655 \mathrm{~nm}$. A calibration curve was obtained by using $2-12 \mathrm{mg} / \mathrm{L} \mathrm{LP}$ as a standard $(y=0.08 x-0.14$, with LP concentration $(x)$ expressed in $\mathrm{mg} / \mathrm{L}, R^{2}=0.985$ ). The LP concentration of each milk sample was calculated according to the equation of the calibration curve.

\subsection{Evaluation of LP detection by the test strip}

The concentration of LP in five milk samples was determined using the test strip method. Each determination was carried out six times. The coefficient of variation $(\mathrm{CV})$ of the estimates was calculated.

To obtain the minimum LP concentration detectable by the test strip, a milk sample containing $5 \mathrm{mg} / \mathrm{L}$ LP was diluted with deionized water to $2.000,1.000,0.500,0.050$, and $0.025 \mathrm{mg} / \mathrm{L}$. The LP concentration of each diluted sample was determined using the test strip. Each determination consisted of three replicates.

The correlation between the results from the test strip method and the TMB detection method was determined based on estimates of the LP concentration in sixteen milk samples.

\subsection{Statistical analyses}

Three independent experiments were conducted to optimize the test strip for the measurement of LP, including tests on the effects of the $\mathrm{pH}$ of the buffer solutions, TMB and $\mathrm{H}_{2} \mathrm{O}_{2}$ concentrations, and the selection of surfactants. SPSS 17.0 for windows (SPSS Inc., Chicago, IL, USA) was used for statistical analysis. Data are expressed as means with standard deviations (SD). Significant differences $(P<0.05)$ among means were identified using Duncan's multiple range tests and independent sample $t$-tests.

\section{Results and discussion}

\subsection{Effects of $\mathrm{pH}$ of the buffer solution on test strip detection}

LP has high catalytic activity at its optimum $\mathrm{pH}$ value. In this test, the optimum $\mathrm{pH}$ value of $\mathrm{LP}$ was determined by using TMB as the chromogenic substrate. The effects of different $\mathrm{pH}$ values of the $0.1 \mathrm{~mol} / \mathrm{L} \mathrm{CA} / 0.2 \mathrm{~mol} / \mathrm{L} \mathrm{NaP}$ buffer solution on test strip detection are shown in Fig. 2a. Reflective 
intensity significantly decreased in the $\mathrm{pH}$ range from 4.0 to $5.0(P<0.05)$. This indicated that the chromogenic reaction catalyzed by LP was significantly enhanced. However, the reaction rate gradually decreased when the $\mathrm{pH}$ of LP was higher than 5.0, indicating that $\mathrm{LP}$ activity was inhibited. The $\mathrm{pH}$ range of the buffer solutions was narrowed to obtain the optimum $\mathrm{pH}$ value of the test strip (Fig. 2b). The reflective intensity of the test strip decreased in the $\mathrm{pH}$ range from 4.4 to 5.0 , and then increased significantly in the $\mathrm{pH}$ range from 5.0 to $5.2(P<0.05)$. Therefore, the optimum $\mathrm{pH}$ value of the $0.1 \mathrm{~mol} / \mathrm{L}$ $\mathrm{CA} / 0.2 \mathrm{~mol} / \mathrm{L} \mathrm{NaP}$ buffer for LP detection using the test strip was 5.0. This result is in accordance with the studies conducted by Bardsley (1985), Kumar and Bhatia (1999), and Pruitt et al. (1990), who reported that the optimum $\mathrm{pH}$ of the LP catalyzed reaction using ABTS as a substrate lay between 5 and 6 , depending on the concentrations of $\mathrm{ABTS}$ and $\mathrm{H}_{2} \mathrm{O}_{2}$.
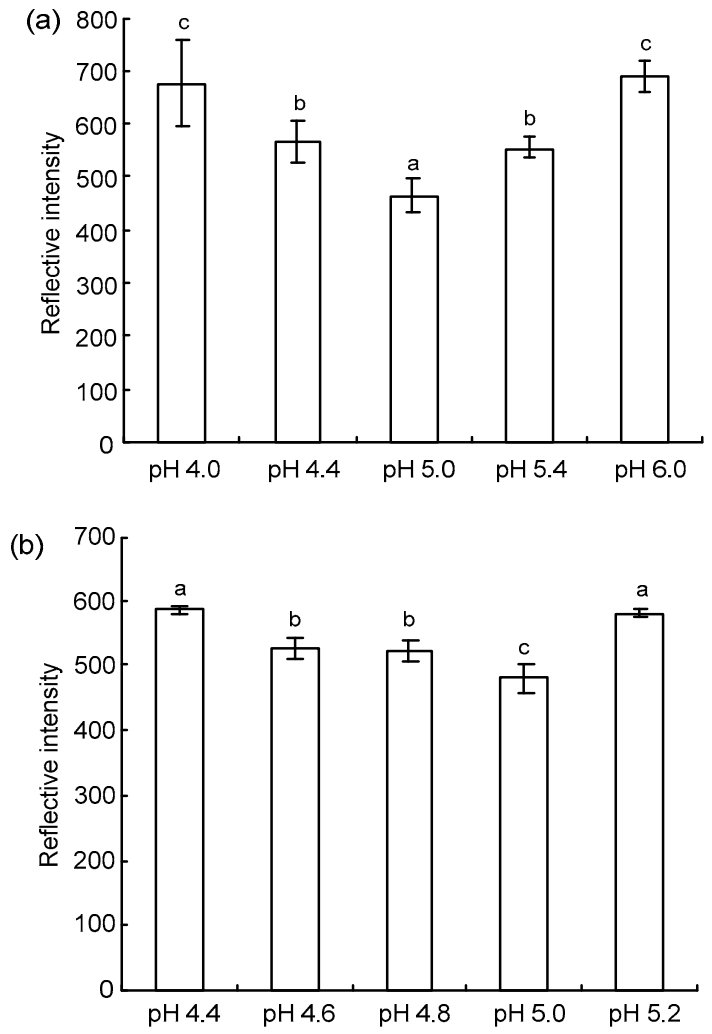

Fig. 2 Effects of $\mathrm{pH}$ values of the $0.1 \mathrm{~mol} / \mathrm{L} \mathrm{CA} / 0.2 \mathrm{~mol} / \mathrm{L}$ NaP buffer on LP detection of test strip

(a) $\mathrm{pH}$ values of the $0.1 \mathrm{~mol} / \mathrm{L} \mathrm{CA} / 0.2 \mathrm{~mol} / \mathrm{L} \mathrm{NaP}$ buffer adjusted at 4.0, 4.4, 5.0, 5.4, and 6.0, respectively. (b) $\mathrm{pH}$ values of the $0.1 \mathrm{~mol} / \mathrm{L} \mathrm{CA} / 0.2 \mathrm{~mol} / \mathrm{L} \mathrm{NaP}$ buffer adjusted at $4.4,4.6,4.8,5.0$, and 5.2, respectively. Different letters mean significant difference $(P<0.05)$. Error bars represent standard deviation $(n=3)$

\subsection{Effects of TMB concentration on test strip detection}

The amount of TMB immobilized in the test strip carrier directly influenced the sensitivity of the test strip. Therefore, it was necessary to investigate the effect of different TMB concentrations. Reflective intensity gradually decreased when the TMB concentration ranged from 10 to $20 \mathrm{mmol} / \mathrm{L}(P<0.05$; Fig. 3a). However, when the TMB concentration was 20 or $25 \mathrm{mmol} / \mathrm{L}$, there was no significant difference in reflective intensity of the test strip $(P>0.05)$. The TMB concentration range was narrowed to obtain the optimal TMB concentration of the test strip (Fig. 3b). The reflective intensity of the test strip declined in the TMB concentration range from 16 to $22 \mathrm{mmol} / \mathrm{L}$, and then increased significantly $(P<0.05)$. Therefore, the minimum reflective intensity of the test strip was obtained at a TMB concentration of $22 \mathrm{mmol} / \mathrm{L}$.
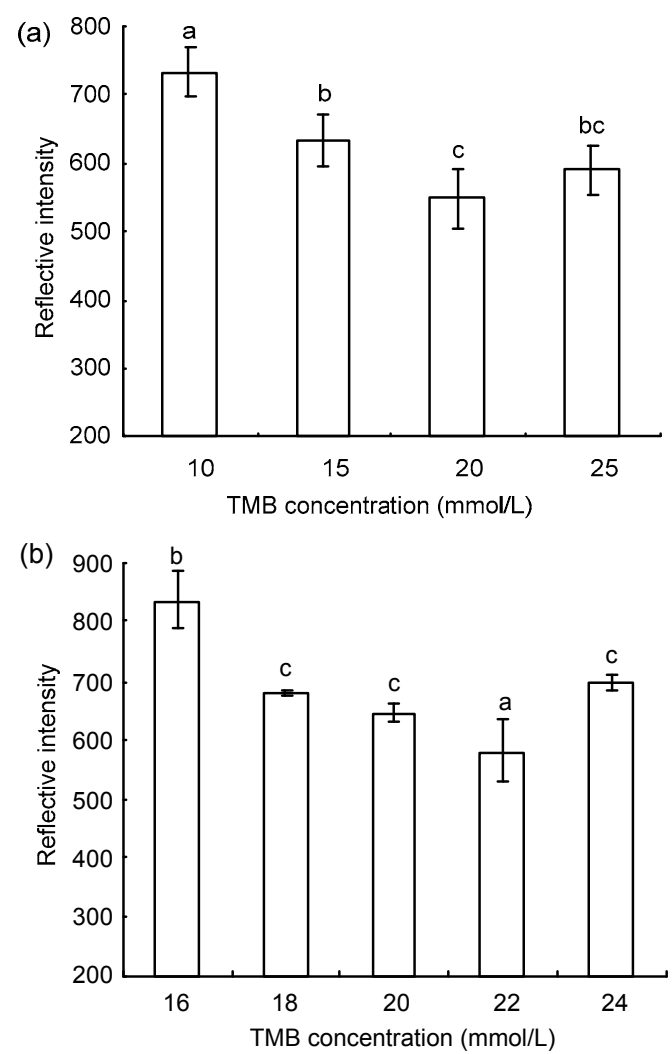

Fig. 3 Effects of different concentrations of TMB on LP detection of test strip

(a) TMB solution prepared at the concentrations of 10, 15, 20, and $25 \mathrm{mmol} / \mathrm{L}$. (b) TMB solution prepared at the concentrations of $16,18,20,22$, and $24 \mathrm{mmol} / \mathrm{L}$. Different letters mean significant difference $(P<0.05)$. Error bars represent standard deviation $(n=3)$ 


\subsection{Effects of different $\mathrm{H}_{2} \mathrm{O}_{2}$ concentrations on test strip detection}

During LP detection, the reaction rate depends on the concentration of the chromogenic substrate, and particularly on the $\mathrm{H}_{2} \mathrm{O}_{2}$ concentration (Pütter and Becker, 1983). So it was important to obtain the optimal $\mathrm{H}_{2} \mathrm{O}_{2}$ concentration for LP detection using the test strip.

The effects of different $\mathrm{H}_{2} \mathrm{O}_{2}$ concentrations on test strip detection are shown in Fig. 4, at a concentration of $22 \mathrm{mmol} / \mathrm{L} \mathrm{TMB}$ and $0.1 \mathrm{~mol} / \mathrm{L} \mathrm{CA} /$ $0.2 \mathrm{~mol} / \mathrm{L} \mathrm{NaP}(\mathrm{pH} \mathrm{5.0})$. The reflective intensity of the test strip decreased with increasing concentrations of $\mathrm{H}_{2} \mathrm{O}_{2}$ from 0.5 to $0.6 \mathrm{mmol} / \mathrm{L}$, and slightly increased when $\mathrm{H}_{2} \mathrm{O}_{2}$ concentration was over $0.6 \mathrm{mmol} / \mathrm{L}$ $(P<0.05)$. This confirmed that inhibition or partial inactivation of LP occurs at higher $\mathrm{H}_{2} \mathrm{O}_{2}$ concentrations (Shindler et al., 1976). To achieve the minimum reflective intensity, $0.6 \mathrm{mmol} / \mathrm{L} \mathrm{H}_{2} \mathrm{O}_{2}$ was selected for the test strip determination of LP activity.

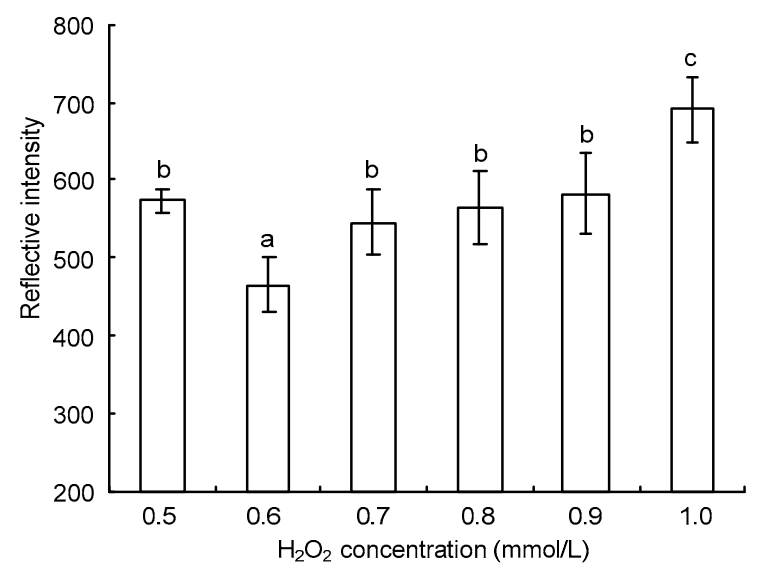

Fig. 4 Effects of varying $\mathrm{H}_{2} \mathrm{O}_{2}$ concentrations on LP detection of test strip

Different letters mean significant difference $(P<0.05)$. Error bars represent standard deviation $(n=3)$

\subsection{Effects of surfactant selection on test strip detection}

The surfactant is composed of hydrophilic and nonpolar hydrophobic groups, which can significantly reduce the surface tension of water. Surfactants are often used as good compatibilizers in spectrophotometric analysis (Li et al., 2012; Liu et al., 2013). For the detection of LP in mature human milk, Shin et al. (2000) used $0.01 \%$ Triton X-100 to enhance the sensitivity and uniformity of the reaction. Therefore, the effects of surfactant selection on LP detection using the test strip were examined. The results showed that $0.5 \%$ SDS, $0.3 \%$ Triton X-100, 0.3\% CTAB, and $0.5 \%$ Tween-20 could significantly enhance the chromogenic reaction $(P<0.05)$, compared with that of the control groups (Fig. 5). There was no significant difference in reflective intensity between $0.5 \%$ Tween-20 and $0.3 \%$ CTAB $(P>0.05)$. Furthermore, the reflective intensity of test strips prepared using $0.5 \%$ Tween-20 was significantly lower than that of strips prepared using $0.5 \%$ SDS and $0.3 \%$ Triton $\mathrm{X}-100(P<0.05)$. Therefore, $0.5 \%$ Tween- 20 or $0.3 \%$ CTAB was used as the optimal surfactant for test strip detection of LP.

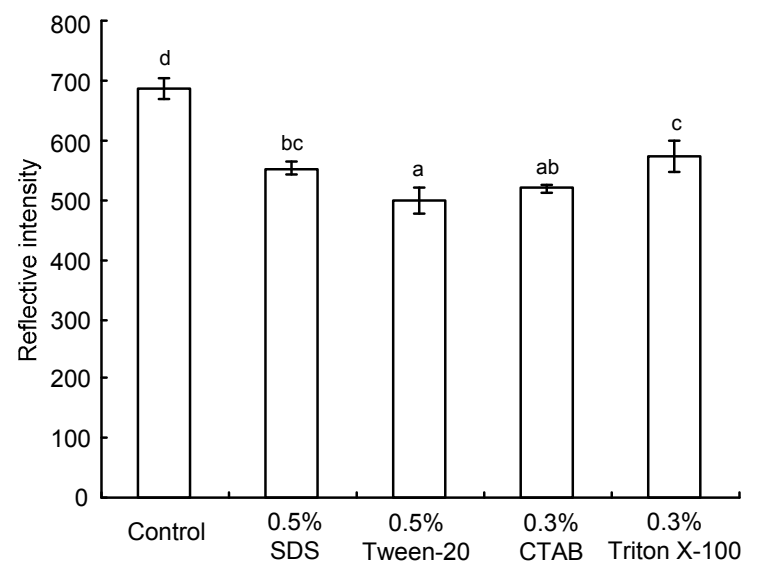

Fig. 5 Effects of surfactant selection on LP detection of test strip

Different letters mean significant difference $(P<0.05)$. Error bars represent standard deviation $(n=3)$

\subsection{Evaluation of LP detection using the test strip}

During test strip detection, the relationships between LP concentrations and the reflective intensity of the test strip were analyzed (Fig. 6). The coefficient of determination was 0.9873 for the equation of the calibration curve $(y=-27.686 x+$ 1199.6). This indicated that the test strip for LP detection was reliable for quantitative determination of LP concentrations.

Reproducibility in the performance of the test strips was investigated using five milk samples containing LP (Table 1). The CV ranged from $2.47 \%$ to $6.72 \%(n=6)$ for all concentrations of LP evaluated. This indicated that test strip detection had good reproducibility. 
Table 1 Reproducibility of LP detection in five milk samples by test strip method $(n=6)$

\begin{tabular}{ccccccccc}
\hline \multirow{2}{*}{ Sample No. } & \multicolumn{7}{c}{ LP concentration (mg/L) } & \multirow{2}{*}{ CV (\%) } \\
\cline { 2 - 8 } & No. 1 & No. 2 & No. 3 & No. 4 & No. 5 & No. 6 & Mean \pm SD & \\
\hline 1 & 19.35 & 19.49 & 20.97 & 16.89 & 19.74 & 16.93 & $18.89 \pm 1.27$ & 6.72 \\
2 & 24.55 & 24.58 & 25.27 & 24.80 & 25.31 & 24.11 & $24.77 \pm 0.61$ & 2.47 \\
3 & 12.81 & 11.11 & 10.97 & 12.66 & 13.02 & 12.95 & $12.25 \pm 0.37$ & 3.06 \\
4 & 19.35 & 20.68 & 21.40 & 20.03 & 21.51 & 22.05 & $20.83 \pm 0.92$ & 4.52 \\
5 & 22.13 & 21.84 & 22.85 & 23.93 & 23.54 & 23.57 & $22.98 \pm 0.96$ & 4.18 \\
\hline
\end{tabular}

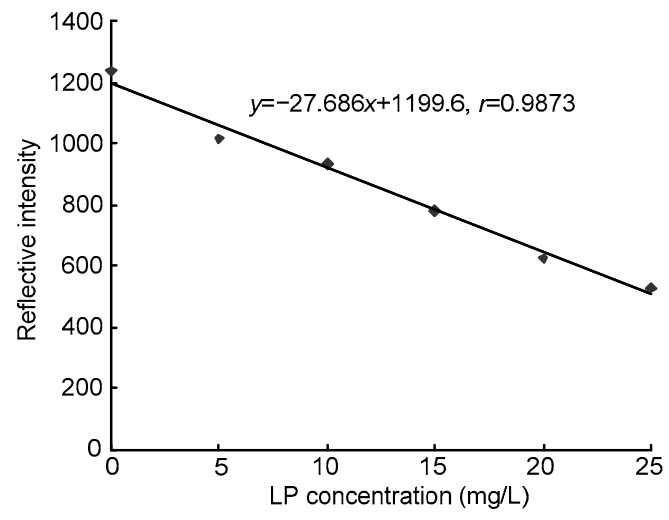

Fig. 6 Typical standard curves for LP assay with the test strip

Data represent the means of three determinations

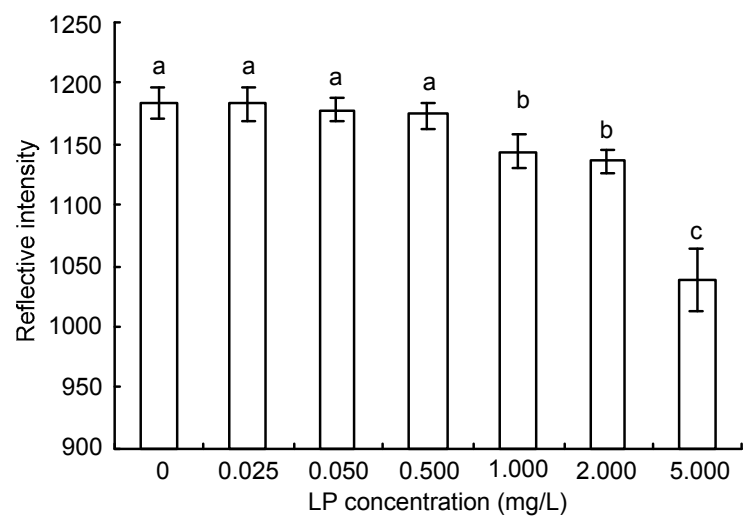

Fig. 7 The lowest $L P$ concentration in milk samples by the test strip detection

Different letters mean significant difference $(P<0.05)$. Error bars represent standard deviation $(n=3)$

The relationship between the LP concentration in milk samples and the reflective intensity of the test strip is shown in Fig. 7. Compared with the control group, there were no significant differences in reflective intensity among the LP concentrations at 0.025 and $0.500 \mathrm{mg} / \mathrm{L}(P>0.05)$. However, compared with the control group, reflective intensity showed significant differences $(P<0.05)$ as the LP concentration rose to 1.000 or $2.000 \mathrm{mg} / \mathrm{L}$. Therefore, the lowest LP concentration detectable by the test strip was between 1.000 and $2.000 \mathrm{mg} / \mathrm{L}$.

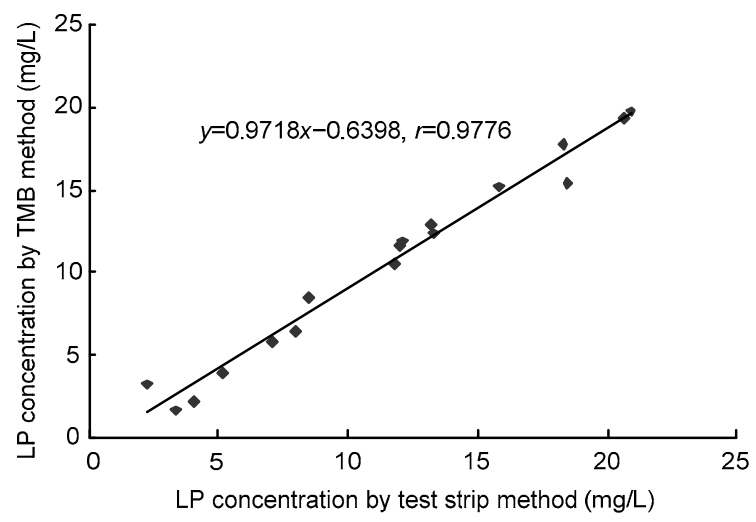

Fig. 8 Correlation between the test strip method for quantifying lactoperoxidase and the TMB method for sixteen milk samples

Data represent the means of three determinations

A comparison of active LP concentrations in sixteen different milk samples estimated using the test strip method and the TMB method led to the regression equation $(y=0.9718 x-0.6398)$ (Fig. 8$)$. The correlation coefficient between active LP concentrations estimated by the test strip method or the TMB method was 0.9776 . Thus, detection by the test strip was highly accurate.

During testing for LP using the test strip, milk samples can be directly examined without pretreatment. Qualitative LP analysis was achieved within a few seconds by observing a color change of the test strip from white to light blue. Quantitative LP analysis could be accomplished using the test strip within $3 \mathrm{~min}$. In summary, the test strip is a quick, convenient, and accurate method for detecting LP.

\section{Conclusions}

A test strip was developed for analysis of LP in raw milk and related dairy products. The optimal preparation conditions of the test strip for LP detection included a $0.1 \mathrm{~mol} / \mathrm{L} \mathrm{CA} / 0.2 \mathrm{~mol} / \mathrm{L} \mathrm{NaP}$ buffer solution (pH 5.0), $22 \mathrm{mmol} / \mathrm{L}$ TMB, $0.6 \mathrm{mmol} / \mathrm{L}$ 
$\mathrm{H}_{2} \mathrm{O}_{2}$, and $0.5 \%$ Tween- 20 or $0.3 \%$ CTAB. The CVs of test strip estimates were below $7 \%$, indicating good repeatability. The lowest LP concentration detectable using the test strip was between 1.000 and $2.000 \mathrm{mg} / \mathrm{L}$. Results from the test strip method for quantification of LP concentration correlated well with those from the TMB method. The test strip method has advantages of rapidity, simplicity and accuracy, and does not require highly skilled laboratory technicians and sophisticated equipment for online LP detection during raw milk collection and its related dairy processing.

\section{Compliance with ethics guidelines}

Hong-xia CHE, Bo TIAN, Li-na BAI, Li-ming CHENG, Li-li LIU, Xiao-na ZHANG, Zhan-mei JIANG, and Xiao-xi $\mathrm{XU}$ declare that they have no conflict of interest.

This article does not contain any studies with human or animal subjects performed by any of the authors.

\section{References}

Bardsley, W.G., 1985. Steady-state kinetics of lactoperoxidasecatalyzed reaction. In: Pruitt, K.M., Tenovuo, J.O. (Eds.), The Lactoperoxidase System: Chemistry and Biological Significance. Marcel Dekker, New York, p.55-87.

Boulares, M., Mankai, M., Hassouna, M., 2011. Effect of activating lactoperoxidase system in cheese milk on the quality of Saint-Paulin cheese. Inter. J. Dairy Technol., 61(1):75-83. [doi:10.1111/j.1471-0307.2010.00646.x]

Fonteh, F.A., Grandison, A.S., Lewis, M.J., 2005. Factors affecting lactoperoxidase activity. Inter. J. Dairy Technol., 58(4):233-236. [doi:10.1111/j.1471-0307.2005.00227.x]

Griffiths, M.W., 1986. Use of milk enzymes as index of heat treatment. J. Food Prot., 49:696-705.

Isobe, N., Kubota, H., Yamasaki, A., et al., 2011. Lactoperoxidase activity in milk is correlated with somatic cell count in dairy cows. J. Dairy Sci., 94(8):3868-3874. [doi:10.3168/jds.2010-4133]

Kumar, R., Bhatia, K.L., 1999. Standardization of method for lactoperoxidase assay in milk. Lait, 79(2):269-274. [doi:10.1051/lait:1999222]

Kussendrager, K.D., van Hooijdonk, A.C.M., 2000. Lactoperoxidase: physico-chemical properties, occurrence, mechanism of action and applications. Brit. J. Nutr., 84(1): 19-25.

Li, B., Dong, Y., Xu, B., 2012. A spectrophotometric method for determining the activity of lipoxygenase activity in rice bran and its enzymatic characteristics study. J. Chin. Inst. Food Sci. Technol., 12(9):192-197 (in Chinese).

Liu, S.J., Qin, W.Q., Liu, W., et al., 2013. Synergistic mechanism of Tween-20 to oleic acid in bauxite flotation. Chin J. Nonferrous Met., 23(8):2284-2289 (in Chinese).
Marks, N.E., Grandison, A.S., Lewis, M.J., 2001. Challenge testing of the lactoperoxidase system in pasteurised milk. J. Appl. Microbiol., 91(4):735-741. [doi:10.1046/j.13652672.2001.01435.x]

Mazri, C., Sánchez, L., Ramos, S.J., et al., 2012. Effect of high-pressure treatment on denaturation of bovine lactoferrin and lactoperoxidase. J. Dairy Sci., 95(2):549-557. [doi:10.3168/jds.2011-4665]

Montiel, R., Bravo, D., de Alba, M., et al., 2012. Combined effect of high pressure treatments and the lactoperoxidase system on the inactivation of Listeria monocytogenes in cold-smoked salmon. Innov. Food Sci. Emerg. Techol., 16:26-32. [doi:10.1016/j.ifset.2012.03.005]

Pinho, C.R.G., Franchia, M.A., Tribsta, A.A.L., et al., 2011. Effect of ultra high pressure homogenization on alkaline phosphatase and lactoperoxidase activity in raw skim milk. Procedia Food Sci., 1:874-878. [doi:10.1016/j. profoo.2011.09.132]

Pruitt, K.M., Kamau, D.N., Miller, K., et al., 1990. Quantitative, standardized assays for determining the concentrations of bovine lactoperoxidase, human salivary peroxidase, and human myeloperoxidase. Anal. Biochem., 191(2):278-286. [doi:10.1016/0003-2697(90)90220-4]

Pütter, J., Becker, R., 1983. Peroxidases. In: Bergmeyer, H.U. (Ed.), Methods of Enzymatic Analysis. Verlag, Florida Chemie, p.286-293.

Seifu, E., Buys, E.M., Donkin, E.F., 2005. Significance of the lactoperoxidase system in the dairy industry and its potential applications. Food Sci. Technol., 16(4):137-154. [doi:10.1016/j.tifs.2004.11.002]

Shakeel-ur-Rehman, Farkye, N.Y., 2003. Lactoperoxidase. In: Roginski, R., Fuquay, J.W., Fox, P.F. (Eds.), Encyclopedia of Dairy Science. Academic Press, Amsterdam, p.939-941.

Shimizu, E., Kobayashi, T., Wakabayashi, H., et al., 2011. Effects of orally administered lactoferrin and lactoperoxidasecontaining tablets on clinical and bacteriological profiles in chronic periodontitis patients. Inter. J. Dent., 2011: $1-9$.

Shin, K., Tomita, M., Lönnerdal, B., 2000. Identification of lactoperoxidase in mature human milk. J. Nutr. Biochem., 11(2):94-102. [doi:10.1016/S0955-2863(99)00082-0]

Shindler, J.S., Childs, R.E., Bradsley, W.G., 1976. Peroxidase from human cervical mucus, the isolation and characterisation. Eur. J. Biochem., 65(2):325-331. [doi:10. 1111/j.1432-1033.1976.tb10345.x]

Singh, A.K., Singh, N., Sharma, S., et al., 2008. Crystal structure of lactoperoxidase at $2.4 \AA$ resolution. J. Mol. Biol., 376(4):1060-1075. [doi:10.1016/j.jmb.2007.12.012]

Tenovuo, J., 2002. Clinical applications of antimicrobial host proteins lactoperoxidase, lysozyme and lactoferrin in xerostomia: efficacy and safety. Oral Dis., 8(1):23-29. [doi:10.1034/j.1601-0825.2002.1o781.x]

van Hooijdonk, A.C.M., Kussendrager, K.D., Steijns, J.M., 2000. In vivo antimicrobial and antiviral activity of 
components in bovine milk and colostrums involved in non-specific defence. Br. J. Nutr., 84(Suppl. 1):S127S134.

Wolfson, L.M., Sumner, S.S., 1993. Antibacterial activity of the lactoperoxidase system: a review. J. Food Prot., 56(10):887-892.

\section{中文概要}

题 目: 乳过氧化物酶快速检测试纸的研制

目 的: 开发快速、灵敏和准确的乳过氧化物酶检测方法, 用于原料乳验收及相关乳制品加工中对乳过氧 化物酶的检测。

创新点: 首次以试纸检测方法代替传统的试管检测法, 借 助便携式光电测色仪实现对乳过氧化物酶的定 量检测分析。

方 法: 以反光值为检测指标, 从缓冲液 $\mathrm{pH}$ 、四甲基联
苯胺 (TMB) 浓度、过氧化氢 $\left(\mathrm{H}_{2} \mathrm{O}_{2}\right)$ 浓度和表 面活性剂四个方面, 优化篮选检测试纸的最佳制 作条件; 通过精密度试验、最低检出浓度和与试 管检测法相关性分析, 评价试纸检测法的可靠性 和准确性。

结 论: 试纸检测体系的优化结果为 $0.1 \mathrm{~mol} / \mathrm{L}$ 柠檬酸/ $0.2 \mathrm{~mol} / \mathrm{L}$ 磷酸氢二钠溶液（pH 5.0），22 mmol/L TMB， $0.5 \%$ Tween- 20 或 $0.3 \%$ 溴化十六烷基三甲 铵 (CTAB), 和 $0.6 \mathrm{mmol} / \mathrm{L} \mathrm{H}_{2} \mathrm{O}_{2}$ 。检测试纸的 精密度较好, 变异系数在 $2.47 \%$ 6.72\%（表 1）; 最低检出浓度为 $1.000 \sim 2.000 \mathrm{mg} / \mathrm{L}$ (图 7)；与 试管法检测结果的相关系数为 0.9776 (图 8)。 因此, 试纸检测法是一种快速、灵敏和准确的乳 过氧化物酶检测技术, 可满足原料乳验收及相关 乳制品加工中对乳过氧化物酶检测的需求。

关键词: 乳过氧化物酶; 试纸; 快速检测; 原乳; 四甲基 联苯胺 